\title{
Noite e Neblina: um livro sobre um filme na história
}

\section{Patrícia Machado e Thais Blank}

\section{Resenha}

LINDEPERG, Sylvie. Nuit et brouillard, un film dans

l'histoire. Paris: Odile Jacob, 2007.

Patrícia Machado | patricia.furtado.machado@gmail.com Doutoranda em Comunicação e Cultura pela Universidade Federal do Rio de Janeiro (UFRJ).

Thais Blank | thaisblank@gmail.com Doutoranda em Comunicação e Cultura pela Universidade Federal do Rio de Janeiro (UFRJ), em cotutela com a Universidade Paris 1.
Em 29 de abril de 1956, o documentário Noite e neblina, de Alain Resnais, foi exibido pela primeira vez no Festival de Cannes. A delegação alemã considera 0 filme ofensivo e como ato de protesto se retira do Festival. Um pouco mais de uma década separa o fim da Segunda Guerra Mundial da data de estreia do filme. Os representantes alemães acreditam que as duras imagens dos campos de concentração podem prejudicar uma Alemanha em plena reconstrução e que não sabe, ainda, como lidar com a memória da guerra.

Esse e outros episódios ocorridos em torno da realização e circulação de Noite e neblina (1956) são investigados em detalhe no livro Nuit et brouillard, un film dans l'histoire (Odile Jacob, 2007), da historiadora Sylvie Lindeperg. Infelizmente ainda não lançada no Brasil, a obra foi considerada na França como um trabalho exemplar e vem influenciando uma série de pesquisadores que exploram as relações entre cinema, história e arquivo - tema ao qual a professora da Universidade Paris I se dedica há mais de dez anos. ${ }^{1}$ 
Canonizado como um clássico do cinema, os planos de Noite e neblina povoam, até hoje, os nossos piores pesadelos, conferindo imagem aos fatos dramáticos do Holocausto. No entanto, o que em geral desconhecemos, é que o filme percorreu um longo e tortuoso caminho atravessado por disputas políticas e ideológicas. São pelos meandros desse caminho que Sylvie Lindeperg conduz os leitores do seu livro.

Desenvolvendo um método de análise que denomina de cinema em ação, Lindeperg propõe uma prática de pesquisa que consiste em partir do filme pronto, da imagem projetada na tela, em direção ao filmen-train-de-se-faire. Sua proposta é atravessar a tela do cinema para tentar reencontrar os traços da história que a obra projetada não conseguiu reter. Para tanto, divide 0 livro em duas partes. Na primeira, Lindeperg realiza um mergulho nos arquivos e na fabricação do documentário. $\mathrm{Na}$ segunda, a autora se dedica a estudar os olhares portados sobre a obra e as diferentes interpretações e sentidos que o filme ganhou ao longo do tempo. A pesquisadora recupera assim as inúmeras versões dos roteiros, os documentos de censura, as cartas trocadas entre os membros da equipe, as diferentes etapas de montagem, as críticas na imprensa e os percursos variados traçados pelo documentário após sua realização.

Nesse trajeto, Lindeperg localiza o filme de Resnais no centro dos debates de uma política da memória que se encontrava em plena construção na França do pós-guerra, ressaltando que 0 documentário trouxe à tona as perversões do sistema concentracional em um momento em que 0 Holocausto e seus efeitos não haviam sido decifrados. A autora afirma que, na estréia do filme, a memória estabelecida em torno dos eventos da guerra se ligava às perdas e ganhos da Resistência Francesa, e que a diferença entre campos de concentração e campos de extermínio não estava completamente esclarecida.

Um dos movimentos mais interessantes do método de análise proposto por Lindeperg é mostrar as mudanças provocadas, pelo deslocamento no tempo, no olhar portado sobre uma imagem. No momento da filmagem de Noite e neblina, a equipe do documentário não tinha conhecimento da raridade de determinadas imagens que possuíam em mãos. Só anos mais tarde, algumas fotografias foram decifradas ou reinterpretadas. Esse é o caso do célebre plano da menina que olha para a lente do cinegrafista nazista de dentro do trem que seguiria para Auschwitz. Imortalizada pelo filme de Resnais, essa imagem se tornará símbolo da Destruição dos Judeus da Europa. No entanto, a busca da história dessa menina iria revelar, já na década de 1980, que ela era cigana e não judia.

Exemplos como esse permitem à autora produzir uma reflexão mais ampla sobre o gesto do pesquisador que olha a história a partir do 
presente para acrescentar novas camadas ao que sabe do passado. Chamando atenção para 0 olhar que cada época permite, Sylvie Lindeperg reapresenta o filme de Resnais mostrando que ainda há muito o que apreender com um documentário, já muitas vezes visto. Para a historiadora, isso é possível porque o filme escapa de uma memória museificada, que eterniza um horror esquemático dos campos de concentração, na medida em que produz a possibilidade de uma experiência que permanece nos espectadores.

Para além das imagens, a força do livro de Lindeperg reside na atenta análise estética e rigorosa pesquisa historiográfica. Seguindo 0 pensamento benjaminiano de que é possível descobrir na análise de um pequeno momento singular o cristal do evento total, Lindeperg nos permite pensar através de Noite e neblina a potência das imagens de arquivo a partir do movimento de sua retomada. 


\section{Expediente}

A revista E-Compós é a publicação científica em formato eletrônico da Associação Nacional dos Programas de Pós-Graduação em Comunicação (Compós). Lançada em 2004, tem como principal finalidade difundir a produção acadêmica de pesquisadores da área de Comunicação, inseridos em instituições do Brasil e do exterior.
E-COMPÓS I www.e-compos.org.br I E-ISSN 1808-2599

Revista da Associação Nacional dos Programas

de Pós-Graduação em Comunicação.

E-compós, Brasilia, v.16, n.1, jan./abr. 2013

A identificação das edições, a partir de 2008,

passa a ser volume anual com três números.

\section{CONSELHO EDITORIAL}

Afonso Albuquerque, Universidade Federal Fluminense, Brasil Alberto Carlos Augusto Klein, Universidade Estadual de Londrina, Brasil Álvaro Larangeira, Universidade Tuiuti do Paraná, Brasil André Luiz Martins Lemos, Universidade Federal da Bahia, Brasil Ângela Freire Prysthon, Universidade Federal de Pernambuco, Brasil Angela Cristina Salgueiro Marques, Faculdade Cásper Líbero (São Paulo), Brasil Antonio Roberto Chiachiri Filho, Faculdade Cásper Líbero, Brasil Arthur Autran Franco de Sá Neto, Universidade Federal de São Carlos, Brasil Benjamim Picado, Universidade Federal Fluminense, Brasil César Geraldo Guimarães, Universidade Federal de Minas Gerais, Brasil Cristiane Freitas Gutfreind, Pontifícia Universidade Católica do Rio Grande do Sul, Brasil

Denilson Lopes, Universidade Federal do Rio de Janeiro, Brasil Eduardo Peñuela Cañizal, Universidade Paulista, Brasil

Eduardo Vicente, Universidade de São Paulo, Brasil Eneus Trindade, Universidade de São Paulo, Brasil Erick Felinto de Oliveira, Universidade do Estado do Rio de Janeiro, Brasil Florence Dravet, Universidade Católica de Brasília, Brasil Gelson Santana, Universidade Anhembi/Morumbi, Brasil Gislene da Silva, Universidade Federal de Santa Catarina, Brasil Guillermo Orozco Gómez, Universidad de Guadalajara Gustavo Daudt Fischer, Universidade do Vale do Rio dos Sinos, Brasil Hector Ospina, Universidad de Manizales, Colômbia Herom Vargas, Universidade Municipal de São Caetano do Sul, Brasil Inês Vitorino, Universidade Federal do Ceará, Brasil Jay David Bolter, Georgia Institute of Technology Jeder Silveira Janotti Junior, Universidade Federal de Pernambuco, Brasil John DH Downing, University of Texas at Austin, Estados Unidos José Afonso da Silva Junior, Universidade Federal de Pernambuco, Brasil José Carlos Rodrigues, Pontifícia Universidade Católica do Rio de Janeiro, Brasil José Luiz Aidar Prado, Pontifícia Universidade Católica de São Paulo, Brasil Kelly Cristina de Souza Prudêncio, Universidade Federal do Paraná, Brasil.
Laan Mendes Barros, Universidade Metodista de São Paulo, Brasil Lance Strate, Fordham University, USA, Estados Unidos Lorraine Leu, University of Bristol, Grã-Bretanha Lucia Leão, Pontifícia Universidade Católica de São Paulo, Brasil Malena Segura Contrera, Universidade Paulista, Brasil

Márcio de Vasconcellos Serelle, Pontifícia Universidade Católica de Minas Gerais, Brasil

Maria Aparecida Baccega, Universidade de São Paulo e Escola Superior de Propaganda e Marketing, Brasil

Maria Ataide Malcher, Universidade Federal do Pará, Brasil

Maria das Graças Pinto Coelho, Universidade Federal do Rio Grande do Norte, Brasil Maria Immacolata Vassallo de Lopes, Universidade de São Paulo, Brasil Maria Luiza Martins de Mendonça, Universidade Federal de Goiás, Brasil Mauro de Souza Ventura, Universidade Estadual Paulista, Brasil Mauro Pereira Porto, Tulane University, Estados Unidos Mirna Feitoza Pereira, Universidade Federal do Amazonas, Brasil Nilda Aparecida Jacks, Universidade Federal do Rio Grande do Sul, Brasil Osvando J. de Morais, Universidade de Sorocaba, Brasil Potiguara Mendes Silveira Jr, Universidade Federal de Juiz de Fora, Brasil Renato Cordeiro Gomes, Pontifícia Universidade Católica do Rio de Janeiro, Brasil Robert K Logan, University of Toronto, Canadá

Ronaldo George Helal, Universidade do Estado do Rio de Janeiro, Brasil Rose Melo Rocha, Escola Superior de Propaganda e Marketing, Brasil Rossana Reguillo, Instituto de Estudos Superiores do Ocidente, Mexico Rousiley Celi Moreira Maia, Universidade Federal de Minas Gerais, Brasil Sebastião Guilherme Albano da Costa, Universidade Federal do Rio Grande do Norte, Brasil

Simone Maria Andrade Pereira de Sá, Universidade Federal Fluminense, Brasil Tiago Quiroga Fausto Neto, Universidade de Brasília, Brasil Suzete Venturelli, Universidade de Brasília, Brasil Valerio Fuenzalida Fernández, Puc-Chile, Chile

Veneza Mayora Ronsini, Universidade Federal de Santa Maria, Brasi Vera Regina Veiga França, Universidade Federal de Minas Gerais, Brasil

\section{COMISSÃO EDITORIAL}

Adriana Braga I Pontifícia Universidade Católica do Rio de Janeiro, Brasil

Felipe Costa Trotta I Universidade Federal Fluminense, Brasil

CONSULTORES AD HOC

Bruno Campanella, Universidade Federal Fluminense, Brasil

Christa Berger, Universidade do Vale do Rio dos Sinos, Brasil

Edison Gastaldo, Universidade Federal Rural do Rio de Janeiro, Brasil

José Luiz Braga, Universidade do Vale do Rio dos Sinos, Brasil

\section{EDIÇÃO DE TEXTO E RESUMOS I Susane Barros}

SECRETÁRIA EXECUTIVA I Juliana Depiné

EDITORACã̃ ELETRÔNICA I Roka Estúdio
COMPóS I www.compos.org.br

Associação Nacional dos Programas de Pós-Graduação em Comunicação

Presidente

Julio Pinto

Pontifícia Universidade Católica de Minas Gerais, Brasil juliopinto@pucminas.br

Vice-presidente

Itania Maria Mota Gomes

Universidade Federal da Bahia, Brasil

itania@ufba.br

Secretária-Geral

Inês Vitorino

Universidade Federal do Ceará, Brasil

inesvic@gmail.com 